\begin{tabular}{|c|l|}
\hline Title & Adsorption of Heavy Metal Ions to Floc-Type Biosorbents \\
\hline Author(s) & Seki, Hideshi; Suzuki, A kira \\
\hline Citation & $\begin{array}{l}\text { Journal of Colloid and Interface Science, 249(2), 295-300 } \\
\text { https://doi.org/L0.1006/cis.2002.8297 }\end{array}$ \\
\hline Issue Date & 2002-05-15 \\
\hline Doc URL & http://hdl.handle.net/2115/44073 \\
\hline Type & article (author version) \\
\hline File Information & 2002b.pdf \\
\hline
\end{tabular}

Instructions for use 


\title{
Adsorption of Heavy Metal Ions to Floc-type Biosorbents
}

\author{
HIDESHI SEKI AND AKIRA SUZUKI
}

Division of Marine Biosciences, Graduate School of Fisheries Sciences,

Hokkaido University,

Minato-cho 3-1-1 Hakodate 041-8611, Japan

\begin{abstract}
Abbreviated title:
METAL ADSORPTION TO FLOC-TYPE BIOSORBENTS
\end{abstract}

Hideshi Seki

Division of Marine Biosciences, Graduate School of Fisheries Sciences

Hokkaido University,

Minato-cho 3-1-1 Hakodate 041-8611, Japan

E-mail: seki@elsie.fish.hokudai.ac.jp. 


\begin{abstract}
Adsorption of cadmium and lead ions to floc-type biosorbents was reported in this work. Two types of biosorbents containing a marine microalga, Heterosigma akashiwo (Hada) Hada or a purple non-sulfur bacterium, Rhodobacter sphaeroides were prepared. The microorganisms inactivated by steam sterilization were immobilized in casein floc and cross-linked with glutaraldehyde. In the present immobilizing method, we obtained the biosorbents comprising as much as $67 \%$ of microorganism on a dry-weight basis. Simple metal binding models were applied to explain the adsorption mechanism of bivalent metal ions to the biosorbents. The results showed that casein acted as both the immobilizing material and the adsorbent material. The adsorption of bivalent metal ions to the biosorbents was due to bidentate binding to the acidic sites on casein and monodentate binding to the acidic sites on microorganisms. The metal binding constants and the binding capacities of microorganisms were scarcely influenced by immobilization.
\end{abstract}

Key Words: biosorbent; microorganisms, protein, immobilization, heavy metals 


\section{INTRODUCTION}

Biosorption has received much attention recently due to its potential use in waste treatment process involving removal of toxic heavy metals from a contaminated aqueous environment. Thus many types of biomass have been investigated for use in this application (1-13). An abundant source of potentially metal-sorbing biomass is microorganisms. They are a widely available, inexhaustible, and inexpensive material that exhibit significant specificity for the targeted heavy metal ions.

In the previous studies, we reported about the biosorption characteristics of lead and cadmium ions to a purple nonsulfur bacterium, Rhodobacter sphaeroides and a marine microalga, Heterosigma akashiwo (Hada) Hada (11, 13). Purple bacteria have recently become very promising tools for purifying waste waters and gases (14-17), and the residual waste biomass resulting from water treatment is economically attractive material for biosorbents. H.akashiwo is a major constituent of red tides on the coast of Japan. Red tides emerge suddenly in the eutrophied sea area and cause serious damage to the coastal fishery. Looking at this from another angle, red tide planktons are regarded as an inexhaustible and attractive material for the biosorbent.

However, microorganisms have a serious difficulty in the practical use, that 
is, they are too small to use them as the sole adsorbent. For the practical application, the metal adsorption performance of microorganisms immobilized in a polymeric matrix, silica gel, or other supports has been investigated $(1,4$, $6,10)$.

In the present study, the biosorption characteristics of cadmium and lead ions to floc-type biosorbents containing $R$. sphaeroides or $H$. akashiwo were investigated. The microorganism was immobilized in a casein floc and crosslinked with glutaraldehyde. A potentiometric titration was performed to determine the acid-dissociation characteristics of the acidic sites on the casein floc. Then we tried to apply a monodentate-type adsorption model and a bidentate-type adsorption model used in our previous studies $(11-13,18-20)$ to the adsorption of cadmium and lead ions to the biosorbents. Based on the models, the biosorption mechanism of the biosorbents will be discussed. 


\section{MATERIALS}

Chemicals

Cadmium nitrate, lead nitrate, sodium nitrate, 25\% glutaraldehyde solution, and casein (from milk) were obtained from Wako Pure Chemical Industries (Japan). All chemicals were of reagent-grade quality.

\section{Microorganisms}

Rhodobacter sphaeroides and Heterosigma akashiwo (Hada) Hada were obtained from the Institute for Fermentation, Osaka (Osaka Japan) and the laboratory of chemical oceanography, Hokkaido University, Japan, respectively. $R$. sphaeroides and $H$. akashiwo were grown in batch to the lateexponential growth stage in nutrient-rich medium (21) and f/2 medium (22), respectively. The cells were harvested, inactivated in an autoclave at $120^{\circ} \mathrm{C}$ for $15 \mathrm{~min}$, and washed three times with distilled water. The concentrations of microorganisms were determined by optical measurement at $650 \mathrm{~nm}$ (Hitachi U-1500 Spectrophotometer) and by using the Coulter counter ZM correlated with dry weight. To determine the dry cell weight, $30 \mathrm{~cm}^{3}$ of inactivated cell suspension was filtered through a $0.45-\mu \mathrm{m}$ cellulose nitrate membrane filter and then dried to constant weight at $60^{\circ} \mathrm{C}$. 
Floc-type Biosorbents

A suspension containing an inactivated microorganism (20 dry-g dm $\left.{ }^{-3}\right)$ and casein (10 dry-g dm${ }^{-3}$ ) was mechanically stirred. The $\mathrm{pH}$ of the suspension was adjusted to about $\mathrm{pH} 3$ by $\mathrm{HNO}_{3}\left(1 \mathrm{~mol} \mathrm{dm}^{-3}\right)$ in order to flocculate the microorganism with casein. It was left standing for about 20 min to sediment the floc. The optical density of the supernatant was measured at $650 \mathrm{~nm}$ to determine the amount of microorganism left in the liquid phase. In this study, the optical density of the supernatant was always negligible small. Then the floc was collected by filtration, and it was immersed in an excess glutaraldehyde solution (10 \%) under stirring overnight. The floc, cross-linked with glutaraldehyde, was collected by filtration and washed repeatedly with distilled water. The sedimentation rate of the obtained biosorbent was about 10 $\mathrm{cm} \min ^{-1}$. For the determination of the adsorption characteristics of metal ions to casein floc, the biosorbent containing no microorganism was prepared. Hereafter, the biosorbents containing $R$. spaeroides, $H$. akashiwo, and no microorganism were abbreviated as FCR, FCH and FC, respectively. 


\section{EXPERIMENTAL METHODS}

\section{Potentiometric Titration of Biosorbents}

A suspension $\left(0.3 \mathrm{dm}^{3}\right)$ containing a certain amount of FC, FCH or FCR was mechanically stirred at $30^{\circ} \mathrm{C}$. The ionic strength of the suspension was adjusted to $0.1 \mathrm{~mol} \mathrm{dm}-3$ by the addition of $\mathrm{NaNO}_{3}$. To eliminate $\mathrm{CO}_{2}, \mathrm{~N}_{2}$ gas was continuously bubbled through the system. After reaching thermal equilibrium, the suspension was titrated with a volumetric standard solution of $\mathrm{HNO}_{3}$ or $\mathrm{NaOH}\left(0.1 \mathrm{~mol} \mathrm{dm}^{-3}\right)$. The $\mathrm{pH}$ of the suspension was measured by using a pH meter (Orion Research 520-A). The number of protonated acidic groups of biosorbent was determined from the difference between the bulk proton concentrations in the presence of biosorbent and those in the absence of biosorbent.

\section{Adsorption Experiments}

A suspension of $\mathrm{NaNO}_{3}(0.1 \mathrm{~mol} \mathrm{dm}-3)$ containing a certain amount of biosorbent (FC, FCR, or FCH) was prepared. The $\mathrm{pH}$ of the suspension was adjusted to a desired value by $\mathrm{HNO}_{3}$. After reaching thermal equilibrium at $30^{\circ} \mathrm{C}$, a certain amount of $\mathrm{Pb}\left(\mathrm{NO}_{3}\right)_{2}$ or $\mathrm{Cd}\left(\mathrm{NO}_{3}\right)_{2}$ was added to the suspension. The suspension was stirred for the necessary time to attain the adsorption 
equilibrium, and then the solution was left standing for 20 min to sediment the biosorbent. The $\mathrm{pH}$ and metal ion concentration of the liquid phase were measured. The metal concentration was determined by using an atomic absorption spectrophotometer (Hitachi A-1800). The amount of metal ion adsorbed to biosorbent was determined from the difference between the metal concentrations in the initial and the equilibrium states. To determine the concentration of biosorbent, the suspension was filtered through a filter paper after the adsorption experiment and then dried to constant weight at $60^{\circ} \mathrm{C}$. Distilled water, boiled for 15 minutes and cooled under nitrogen atmosphere, was used in adsorption experiments. 


\section{RESULTS AND DISCUSSION}

\section{Adsorption of Cadmium and Lead Ions to FC}

To determine the necessary time to attain the adsorption equilibrium, preliminary kinetic experiments were conducted. Figure 1 shows the time dependence of lead adsorption to FC, FCH, and FCR. $X_{t}$ and $X$ denote the amount of lead ions adsorbed on 1 dry-g of the biosorbent at time $t$ and at equilibrium, respectively. The adsorption reaction proceeded rapidly in $1 \mathrm{~h}$ and $5 \mathrm{~h}$ or so was enough to attain the equilibrium. From the results, we determined the contact time for the equilibrium experiments as $12 \mathrm{~h}$.

In our previous studies, we reported that the biosorption of bivalent metal ions to microorganisms was due to the monodentate binding of metal ions to carboxylic- and phosphatic-type sites on microorganisms $(11,13)$. Since a casein floc, which is used as an immobilizing agent, also has carboxylic- and phosphatic-type sites, it is expected to act as an adsorbent material.

Figures $2 \mathrm{a}$ and $2 \mathrm{~b}$ show the $\mathrm{pH}$ dependence of the number of cadmium and lead ions adsorbed to FC, respectively. The ordinate of the figures, $X$, represents the equilibrium number of metal ions adsorbed to 1 dry-g of FC.

The following two types of binding reactions are considered in the adsorption of bivalent metal ions. 


$$
-\mathrm{S}^{-}+\mathrm{M}^{2+} \leftrightarrow-\mathrm{SM}^{+} ; K_{M}
$$

or

$$
2(-\mathrm{S})^{-}+\mathrm{M}^{2+} \leftrightarrow(-\mathrm{S})_{2} \mathrm{M} ; K_{M}
$$

-S and $\mathrm{M}^{2+}$ represent the acidic site and the bivalent metal ions, respectively. The adsorption reactions expressed by Eqs.[1] and [2] are called monodentatetype adsorption and bidentate-type adsorption, respectively. The adsorption reactions of bivalent metal ions to acidic sites fixed on rigid planes, such as the sites on the surface of inorganic adsorbents and microorganisms, are usually monodentate-type $(11,13,18)$. In the case of monodentate-type adsorption, the metal binding constant, $K_{M}$, is defined as

$$
K_{M}=\frac{\theta}{(1-\theta)\left[\mathrm{M}^{2+}\right]} \frac{K_{a}+\left[\mathrm{H}^{+}\right]}{K_{a}},
$$

or 


$$
\theta=\frac{K_{a} K_{M}\left[\mathrm{M}^{2+}\right]}{K_{a} K_{M}\left[\mathrm{M}^{2+}\right]+K_{a}+\left[\mathrm{H}^{+}\right]},
$$

where $\theta$ and $K_{a}$ are the fraction of acidic sites occupied by bivalent metal ions and the acid dissociation constant of the acidic site, respectively. The number of metal ions adsorbed to 1 dry-g of FC, $X$, can be obtained as the sum of the number of metal ions bound to carboxylic- and phosphatic-type sites:

$$
X=N_{C} \theta_{C}+N_{P} \theta_{P},
$$

where $N$ is the number of acidic sites on 1 dry-g of FC. The subscripts, $C$ and $P$, represent the carboxylic- and phosphatic-type sites, respectively.

The adsorption reactions of bivalent metal ions to acidic sites on flexible three-dimensional framework, such as the sites on alginate gel, humic acid, and brown algae, are usually bidentate-type $(12,19,20)$. In the case of bidentatetype adsorption, the metal binding constant is defined as

$$
K_{M}=\frac{\theta}{(1-\theta)^{2}\left[\mathrm{M}^{2+}\right]}\left(\frac{K_{a}+\left[\mathrm{H}^{+}\right]}{K_{a}}\right)^{2},
$$

or 


$$
\begin{aligned}
& \theta=\frac{P-\sqrt{P^{2}-4}}{2} \\
& P \equiv 2+\frac{1}{K_{M}\left[\mathrm{M}^{2+}\right]}\left(\frac{K_{a}+\left[\mathrm{H}^{+}\right]}{K_{a}}\right)^{2},
\end{aligned}
$$

The number of metal ions adsorbed to 1 dry-g of FC , $X$, can be obtained as the sum of the number of metal ions bound to carboxylic- and phosphatic-type sites:

$$
X=\left(N_{C} \theta_{C}+N_{P} \theta_{P}\right) / 2 .
$$

The acid dissociation constants, $K_{a}$, and the numbers of acidic sites on 1 dry-g of FC, $N$, determined from potentiometric titration are presented in Table 1. The detailed method to determine $K_{a}$ and $N$ is given elsewhere (11-13, 1820). The parameters for acid dissociation of $R$. sphaeroides and $H$. akashiwo determined in our previous studies $(11,13)$ are also listed in the table.

A nonlinear least-squares method was applied to find the metal binding constants, $K_{M}$, in Eqs. [4] and [7]. The metal binding constants that gave the best fit with the experimental data (in Figs.2a and $2 \mathrm{~b}$ ) are listed in Table 2. The 
metal binding constants of $R$. sphaeroides and $H$. akashiwo determined in our previous studies $(11,13)$ are also listed in the table. It must be noted that the presence of counterions or co-ions in the cell wall material was neglected in this model; therefore, the acid-dissociation constants and the metal-binding constants listed in Tables 1 and 2 are dependent on the salt level.

In the case of monodentate-type adsorption model, the metal binding constants of carboxylic groups were found to be negligible small or zero. Figures 3a and 3b show the comparisons between the experimental number of metal ions adsorbed to FC, $X_{\text {exp }}$, and that calculated from the monodentate-type adsorption model (Eqs.[4] and [5]) and the bidentate-type adsorption model (Eqs.[7] and [8]) with the values in Tables 1 and 2, $X_{\text {cal }}$, respectively. The symbols are the same as those in Figs. 2a and 2b. The figures demonstrate a good agreement of the experimental data with the bidentate-type adsorption model (Fig.3b). The solid lines in Figs.2a and 2b represent the theoretical curve calculated from Eqs. [7]-[9] with the constants listed in Tables 1 and 2. The correlation coefficient between the experimental and the predicted value in Fig.3b was 0.993 . The bidentate-type metal binding constants of cadmium and lead ions to carboxylic-type sites on FC were found to be $6.92 \times 10^{2}$ and $4.67 \times 10^{3} \mathrm{dm}^{3} \mathrm{~mol}^{-1}$, respectively. These values were considerably lower than those to the carboxylic-type sites on alginic acid; $1.48 \times 10^{3} \mathrm{dm}^{3} \mathrm{~mol}^{-1}$ for 
cadmium ion and $1.35 \times 10^{5} \mathrm{dm}^{3} \mathrm{~mol}^{-1}$ for lead ion (12).

\section{Adsorption of Cadmium and Lead Ions to Floc-type Biosorbents}

Figure 4 shows the acid-dissociation curves of FC, FCH, and FCR obtained from the potentiometric titrations. The solid lines represent the theoretical curves calculated using the constants listed in Table 1. Figure 4 demonstrates a good agreement of the experimental data with the theoretical curves. The correlation coefficients between the experimental and the predicted value were 0.992, 0.995, and 1.000 for FC, FCH, and FCR, respectively. However, the experimental data disagreed with the theoretical curves in the $\mathrm{pH}$ range $>8$. This may be due to the difference in the degree of cross-linking of amino-type sites with glutaraldehyde.

Figures 5 and 6 show the $\mathrm{pH}$ dependence of the number of metal ions adsorbed to FCH and FCR, respectively. Assuming that the metal binding abilities of casein and microorganisms are not influenced by the immobilization, the number of metal ions adsorbed to 1 dry-g of the biosorbent, $X$, can be estimated as the sum of the number of metal ions adsorbed to casein floc and microorganism in the biosorbent:

$$
X=f X_{m}+(1-f) X_{C}
$$


where $X_{m}$ and $X_{C}$ represent the number of metal ions adsorbed to 1 dry-g of microorganism and casein, and $f$ represents the weight fraction of microorganism in the biosorbent, respectively.

The solid lines in Figs. 5 and 6 represent the theoretical curves calculated from Eqs.[4], [5], [7], [8] and [9] with the constants in Tables 1 and 2. The number of metal ions adsorbed to 1 dry-g of microorganisms was estimated from Eqs.[4] and [5] (monodentate-type adsorption) and that to casein floc was estimated from Eqs.[7] and [8] (bidentate-type adsorption), respectively. The theoretical curves for the $\mathrm{Pb}$ biosorption are somewhat lower than the experimental values, however, the results show the metal binding abilities of microorganisms and casein are scarcely influenced by immobilization. 


\section{CONCLUSION}

Adsorption of cadmium and lead ions to two types of biosorbents containing a marine microalga, Heterosigma akashiwo (Hada) Hada, or a purple non-sulfur bacterium, Rhodobacter sphaeroides, were investigated. A very ordinary and inexpensive protein, milk casein, was used as an immobilizing material. In the present immobilizing method, we obtained the biosorbents comprising as much as $67 \%$ of microorganism on a dry-weight basis. Casein acted as both the immobilizing material and the adsorbent material. The adsorption of bivalent metal ions to casein was due to bidentate binding to acidic sites. Two types of adsorption model, monodentate- and bidentate-type adsorption model, were applied to clarify the influences of immobilization on the metal binding abilities of microorganisms and casein. The comparison of the model with the experimental data showed that the present immobilization technique scarcely influenced the metal binding abilities of microorganisms and casein. 


\section{APPENDIX: NOMENCLATURE}

$$
\begin{array}{lll}
f & =\text { weight fraction of microorganism in biosorbent } & {[-]} \\
K_{a} & =\text { acid dissociation constants of acidic sites } & {\left[\mathrm{mol}^{-1} \mathrm{dm}^{3}\right]} \\
K_{M} & =\text { metal binding constants } & {\left[\mathrm{dm}^{3} \mathrm{~mol}^{-1}\right]} \\
N & =\text { number of acidic sites } & {\left[\mathrm{mol} \mathrm{g}^{-1}\right]} \\
X & =\text { number of metal ions adsorbed at equilibrium } & {\left[\mathrm{mol} \mathrm{g}^{-1}\right]} \\
X_{t} & =\text { number of metal ions adsorbed at time } t & {\left[\mathrm{~mol} \mathrm{~g}^{-1}\right]} \\
\theta & =\text { fraction of acidic sites occupied by metal ions } & {[-]}
\end{array}
$$

Subscripts

$$
\begin{aligned}
& C=\text { carboxylic groups } \\
& P \quad=\text { phosphatic groups }
\end{aligned}
$$




\section{REFERENCES}

1. Holan, Z.R., Volesky, B., and Prasetyo, I., Biotechnol. Bioeng. 41, 819 (1993).

2. Niu, H., Xu, X.S., Wang, J.H., and Volesky, B., Biotechnol. Bioeng. 42, 785 (1993).

3. Volesky, B., May, H., and Holan, Z.R., Biotechnol. Bioeng. 41, 826 (1993).

4. Volesky, B. and Prasetyo, I., Biotechnol. Bioeng. 43, 1010 (1994).

5. Chang, J., and Hong, J., Biotechnol. Bioeng. 44, 999 (1994).

6. Holan, Z.R., and Volesky, B., Biotechnol. Bioeng. 43, 1001 (1994).

7. McHale, A.P., and McHale, S., Biotechnol. Advances, 12, 647 (1994).

8. Bengtsson, L., Johansson, B., Hackett, T.J., McHale, L., and McHale, A.P., Appl. Microbiol. Biotechnol. 42, 807 (1995).

9. Chong, K.H., and Volesky, B., Biotechnol. Bioeng. 49, 629 (1996).

10. Veglio', F., Beolchini, F., and Toro, L., Ind. Eng. Chem. Res. 37, 1107 (1998)

11. Seki, H., Suzuki, A., and Mitsueda, S., J. Colloid Interface Sci. 197, 185 (1998).

12. Seki, H. and Suzuki, A., J. Colloid Interface Sci. 206, 297 (1998).

13. Seki, H., Suzuki, A., and Iburi, Y., J. Colloid Interface Sci. 229, 196 (2000). 
14. Kobayashi, M., Fujii, K., Shimamoto. I., and Maki, T., Progress Water Technol. 11, 279 (1979).

15. Cork, D.J., Garunas, R., and Sajjad, A., Appl. Environm. Microbiol. 45, 913 (1983).

16. Kim, B.W., Kim, I.K., and Chang, H.N., Biothechnol. Lett. 12, 381 (1990).

17. Maka, A., and Cork, D., J. Ind. Microbiol. 5, 337 (1990).

18. Suzuki, A., Seki, H., and Maruyama, H., J. Chem. Eng. Jpn. 27, 505 (1994).

19. Seki, H. and Suzuki, A., J. Colloid Interface Sci. 171, 490 (1995).

20. Seki, H. and Suzuki, A., Ind. Eng. Chem. Res. 35, 1378 (1996).

21. Doi, Y., Tamaki, A., Kunioka, M., and Soga, K., Appl. Microbiol. Biotechnol. 28, 330 (1988).

22. Guillard, R. R. L. and Ryther, J. H., Can. J. Microbiol., 8, 229 (1962). 


\section{TABLE 1}

Equilibrium Parameters for the Acid Dissociation of

Casein Floc and Microorganisms

\begin{tabular}{lcccc}
\hline & \multicolumn{2}{c}{ Carboxylic group } & \multicolumn{2}{c}{ Phosphatic group } \\
& $p K_{a}$ & $N\left(\mathrm{mmol} \mathrm{g}^{-1}\right)$ & $p K_{a}$ & $N\left(\mathrm{mmol} \mathrm{g}^{-1}\right)$ \\
\hline Casein floc & 4.37 & 0.64 & 6.73 & 0.37 \\
H. akashiwo & 3.90 & 1.79 & 6.64 & 0.70 \\
R. sphaeroides & 4.17 & 0.64 & 6.14 & 0.40 \\
\hline
\end{tabular}


TABLE 2

Metal Binding Constants of Casein Floc and Microorganisms

\begin{tabular}{lcccc}
\hline & \multicolumn{2}{c}{$p K_{M}$ for Cd } & \multicolumn{2}{c}{$p K_{M}$ for $\mathrm{Pb}$} \\
& Carboxylic & Phosphatic & Carboxylic & Phosphatic \\
\hline Casein floc & & & & \\
monodentate & $-*$ & -4.72 & $-*$ & -6.03 \\
bidentate & -2.84 & -6.25 & -3.67 & -8.49 \\
H. akashiwo & -2.36 & -4.47 & -2.89 & -5.53 \\
R. sphaeroides & -2.58 & -3.85 & -3.00 & -4.82 \\
\hline
\end{tabular}

*) negligible small or zero 


\section{Figure Captions}

FIG. 1. Time dependence of lead adsorption to FC (circles), FCH (triangles), and FCR (squares) at $30^{\circ} \mathrm{C}$. Ionic strength was adjusted to $0.1 \mathrm{~mol} \mathrm{dm}^{-3}$ by the addition of $\mathrm{NaNO}_{3}$. The initial concentration of $\mathrm{Pb}\left(\mathrm{NO}_{3}\right)_{2}$ and the concentration of biosorbent were shown in the figure.

FIG. 2. pH dependence of (a) cadmium and (b) lead adsorption to FC at $30^{\circ} \mathrm{C}$. Ionic strength was adjusted to $0.1 \mathrm{~mol} \mathrm{dm}^{-3}$ by the addition of $\mathrm{NaNO}_{3}$. The initial concentration of metal ions and the concentration of FC were shown in the figures. The solid lines represent the theoretical curves calculated from Eqs. [7] and [8].

FIG. 3. Comparison of the experimental amount of metal adsorption to FC and (a) the amount calculated from Eqs. [4]and [5] (monodentate-type adsorption model) and (b) Eqs. [7] and [8] (bidentate-type adsorption model). The symbols are the same as those in Figs. 2a and 2b.

FIG. 4. Acid dissociation curves of acidic groups on FC, FCH, and FCR. The solid lines represent the theoretical curves calculated using the constants listed in Table 1. 
FIG. 5. $\mathrm{pH}$ dependence of cadmium and lead adsorption to $\mathrm{FCH}$ at $30^{\circ} \mathrm{C}$. Ionic strength was adjusted to $0.1 \mathrm{~mol} \mathrm{dm}$-3 by the addition of $\mathrm{NaNO}_{3}$. The initial concentration of metal ions and the concentration of FCH were shown in the figure. The solid lines represent the theoretical curves calculated from Eqs. [4], [5], [7], [8] and [9].

FIG. 6. $\mathrm{pH}$ dependence of cadmium and lead adsorption to FCR at $30^{\circ} \mathrm{C}$. Ionic strength was adjusted to $0.1 \mathrm{~mol} \mathrm{dm}^{-3}$ by the addition of $\mathrm{NaNO}_{3}$. The initial concentration of metal ions and the concentration of FCR were shown in the figure. The solid lines represent the theoretical curves calculated from Eqs. [4], [5], [7], [8] and [9]. 


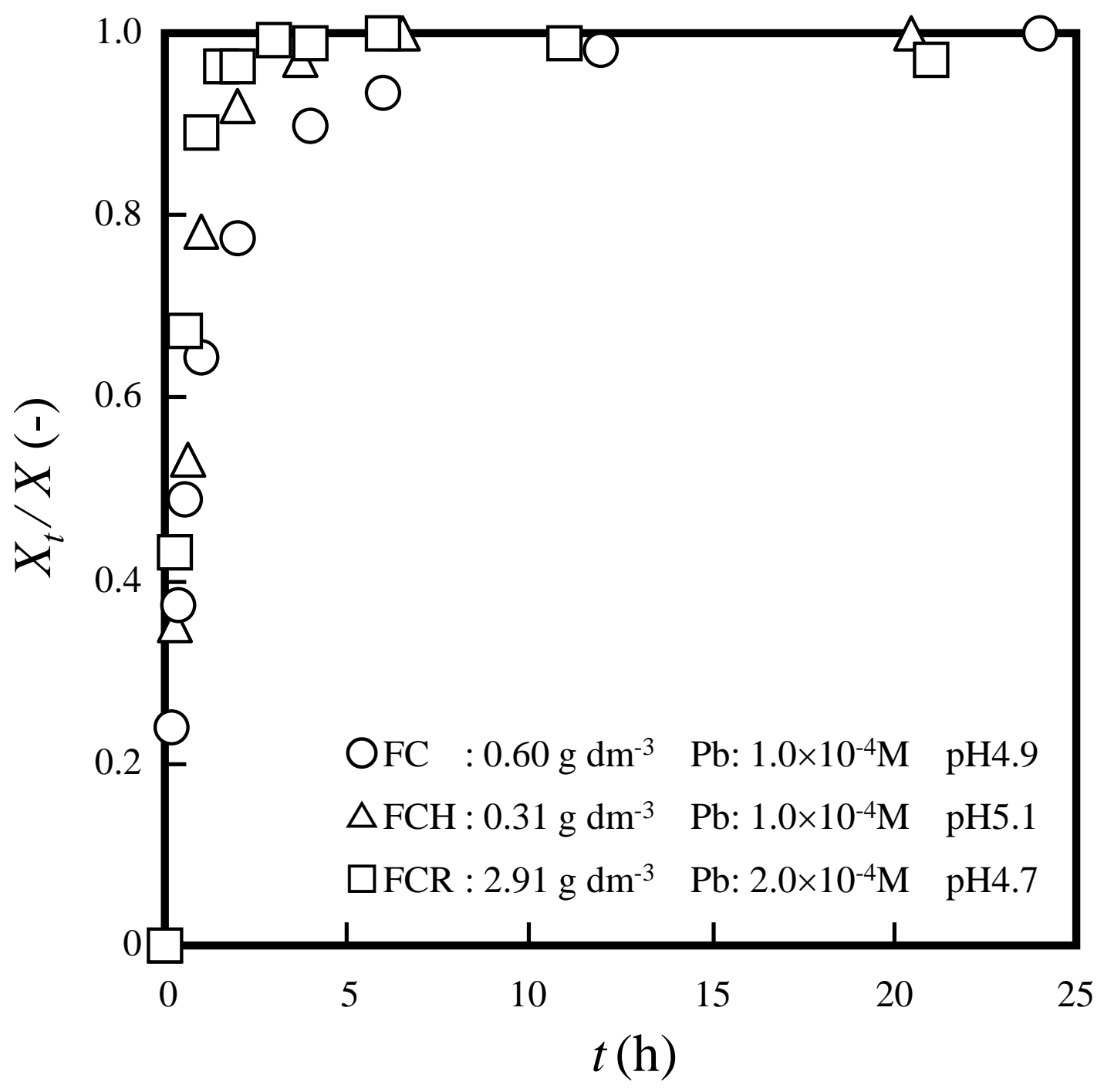



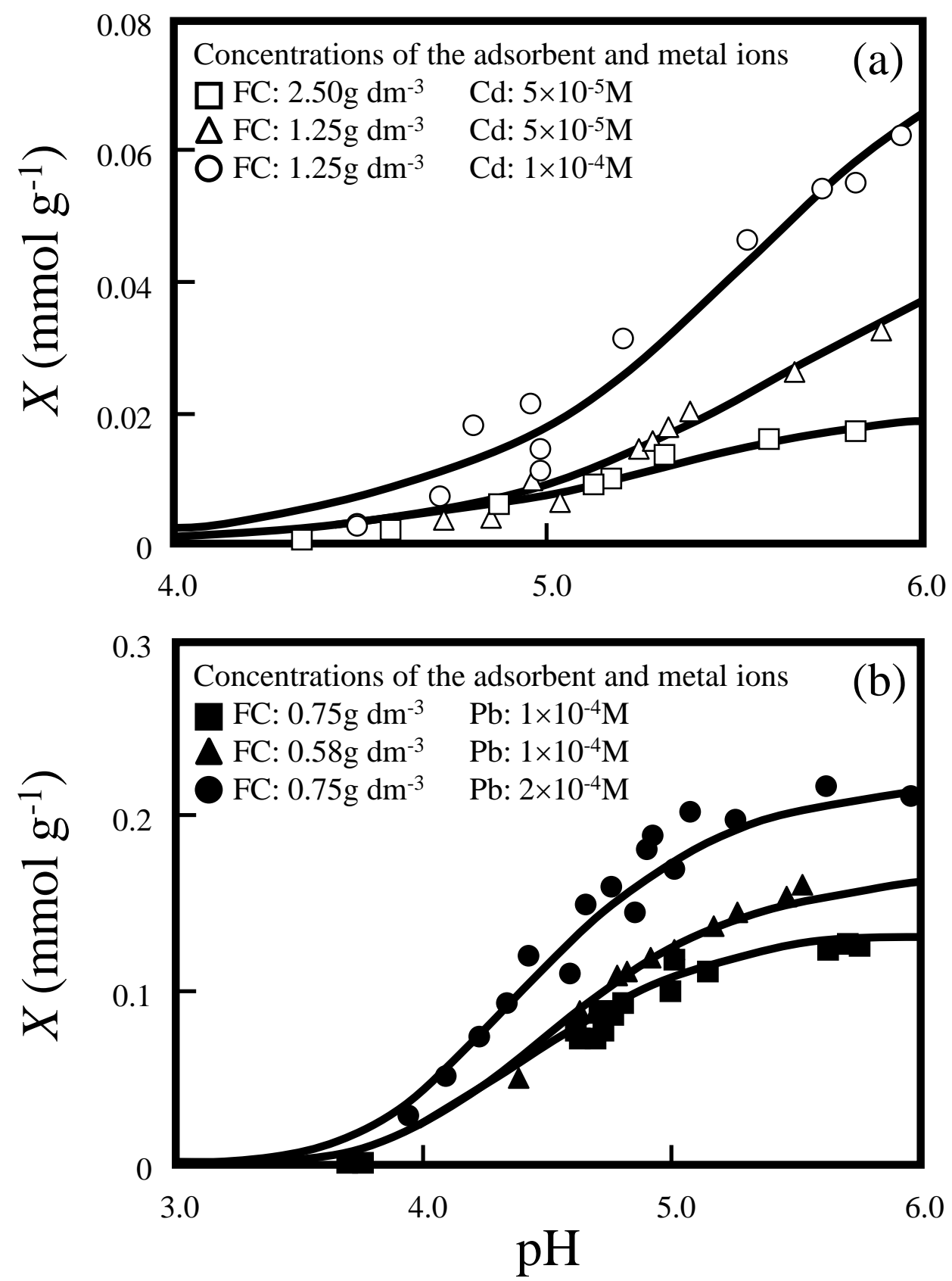


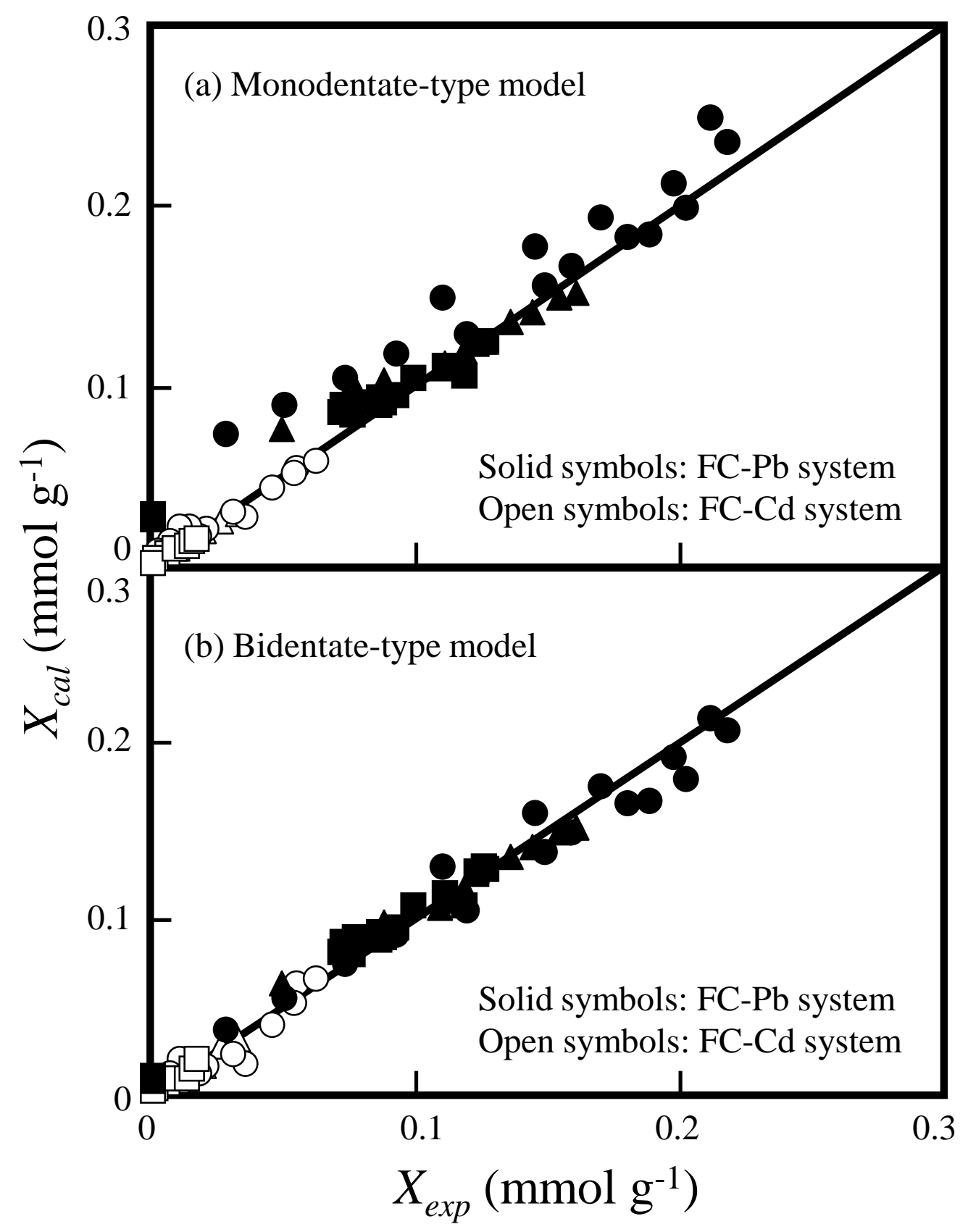




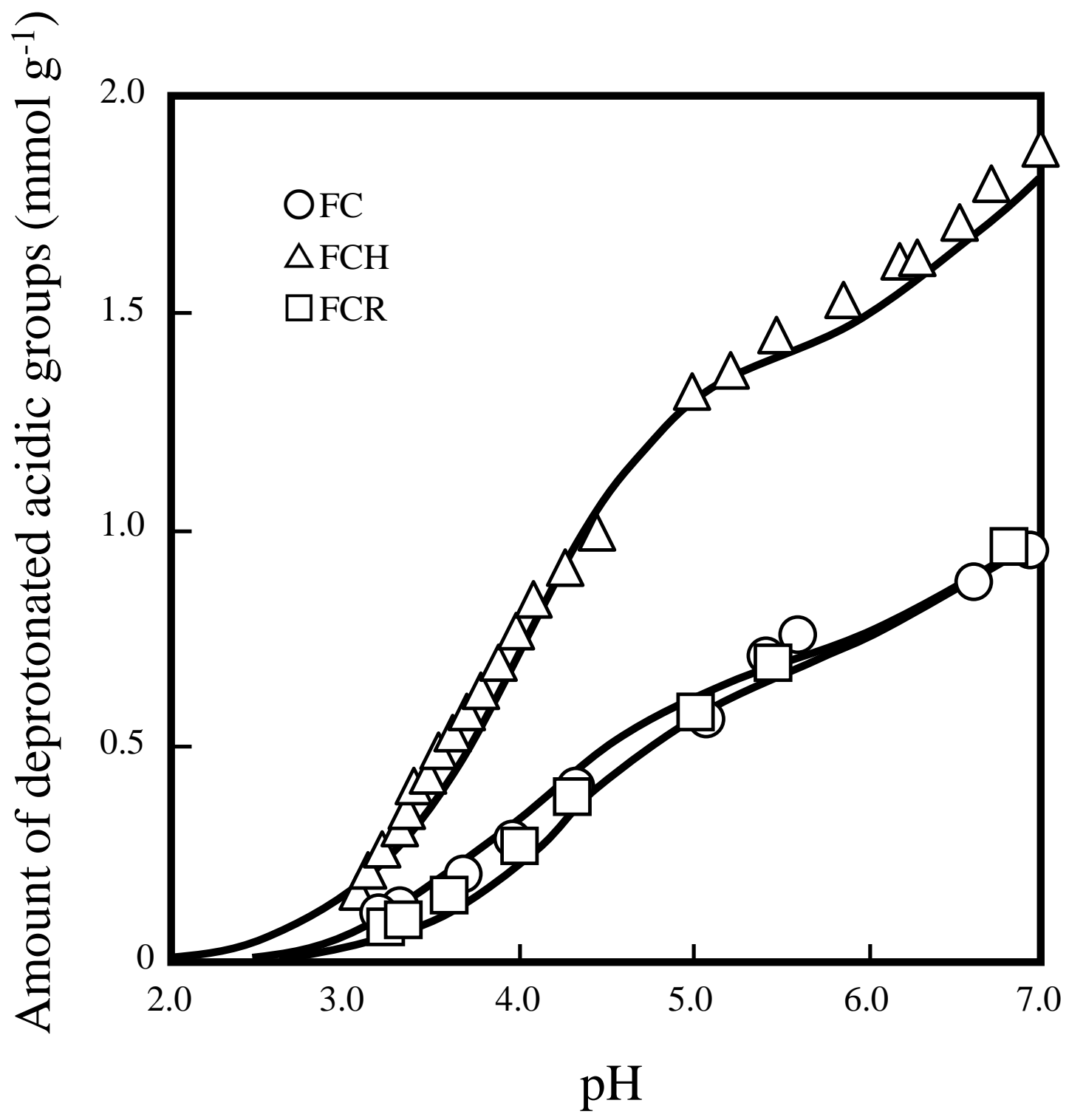




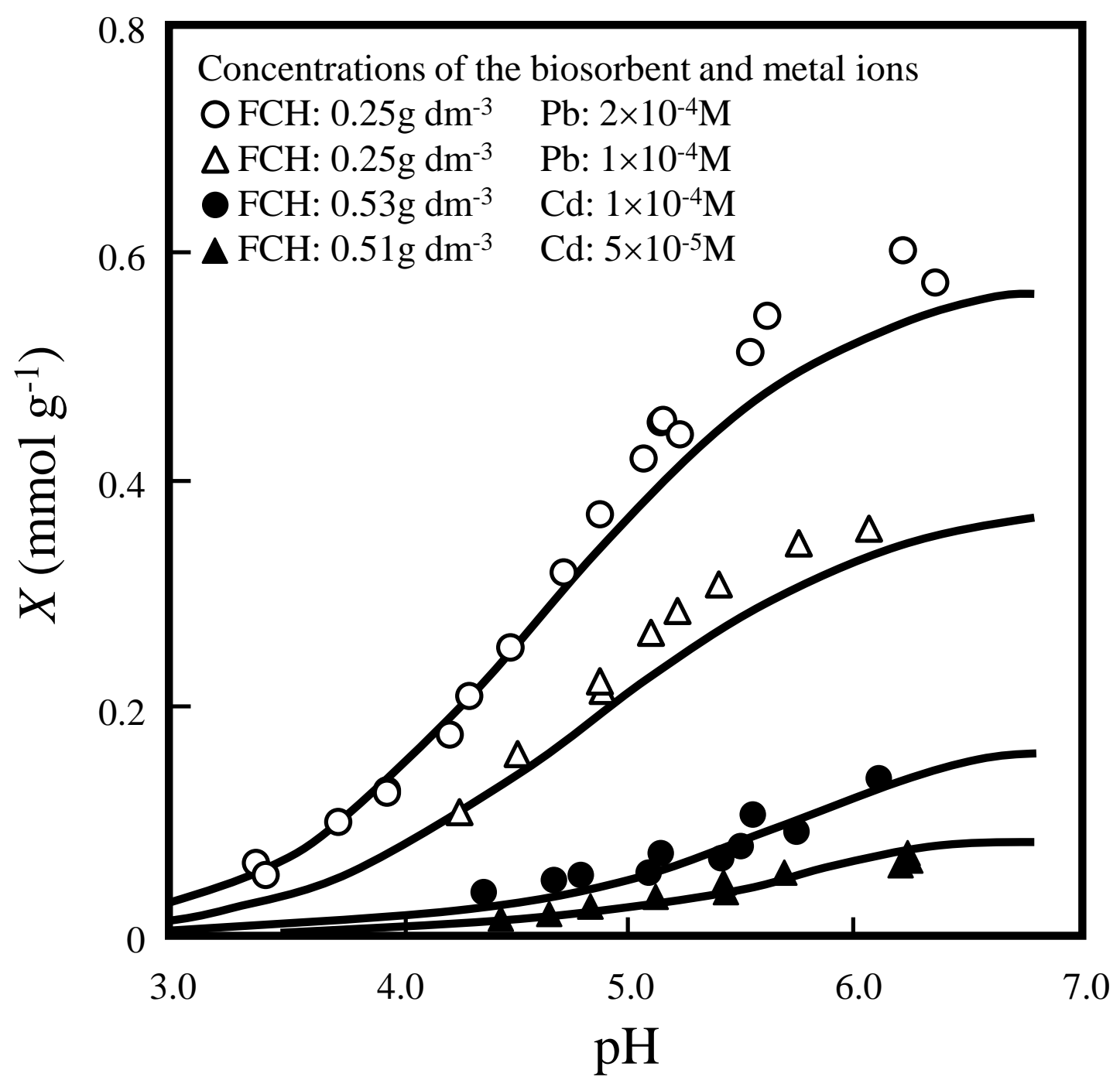




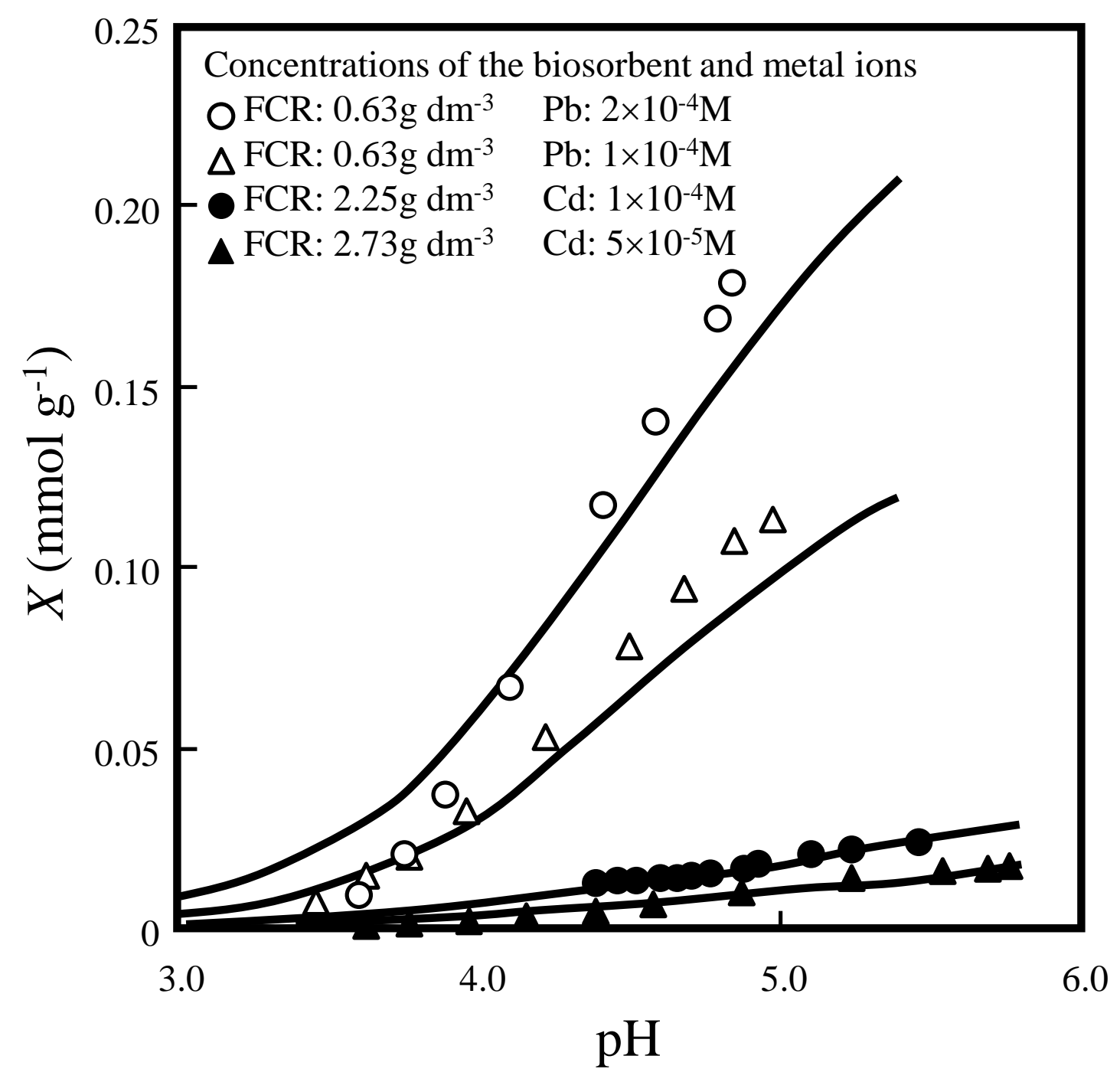

